Chr. Lettl / C. Herstatt / H-G. Gemuenden

\title{
Learning from Users for Radical Innovation,
}

Arbeitspapier Nr. 27,

Technische Universität Hamburg-Harburg, 2004 


\title{
Learning from Users for Radical Innovation
}

\begin{abstract}
In today's environment of rapid technological change companies can not rely on incremental innovations alone. To sustain long-term competitiveness companies need to develop radical innovations as well. Such innovations typically incorporate new and highly complex technologies, create new markets or shift existing market structures, and require user learning as they often induce significant behaviour changes on side of the users. To systematically develop radical innovations firms need to involve the proper actors. One such important external actor in the development process of new products is the user.

Our study focuses on the question what kind of users are able to actively contribute to the development of radical innovations and what firms can learn from them to improve their innovative capability. A multiple case study analysis was conducted in the field of medical technology. Five radical innovation projects were selected including medical robots and computer-assisted navigation systems. The case study analysis reveals that users with a unique set of characteristics can contribute substantially to the development of radical innovations. These users have a high motivation toward new solutions, are open to new technologies, possess diverse competencies, and are embedded into a very supportive context. Manufacturers that took over the ideas and prototypes of the inventive users benefited significantly. By learning from these users, firms were able to significantly improve their radical innovative capability.

The paper contributes to technology and innovation management research in two ways. First, by exploring critical user characteristics for distinct phases of the radical innovation process, we provide first insights how manufacturing firms can more effectively identify and leverage valuable users for their radical innovation work. Thereby, we highlight the involvement of capable users as an effective learning mechanism to improve the radical innovation capability of a firm. Second, new perspectives on lead user research are provided by enriching the lead user concept with other crucial characteristics of innovative users.
\end{abstract}




\section{Introduction}

In today's environment of rapid technological change companies can not rely on incremental innovations alone. To sustain long-term competitiveness companies need to develop radical innovations as well. Such innovations typically incorporate new and highly complex technologies, create new markets or shift existing market structures, and require user learning as they often induce significant behaviour changes on side of the users $[15,19,34]$. To develop radical innovations, companies depend on technological and market related capabilities. One important market related capability is the competence to involve the 'right' users at the 'right' time. Thereby, companies need to know which users are capable to contribute in distinct phases of the radical innovation process.

Due to the high market uncertainties of radical innovations, companies have a high need to involve users as a source of market related knowledge. However, taking into account the characteristics of radical innovations, firms face severe challenges when involving users in the radical innovation process. The reason consists of two barriers on side of the users. First, cognitive limitations can hinder users to deliver valuable inputs (barrier of not knowing). In the idea generation phase users can be 'functionally fixed' to their current use context and therefore unable to develop radically new ideas [1,2]. In addition, users might have difficulties to provide valid evaluations of concepts and prototypes as no reference product for the radical innovation exists [27,35]. Finally, users might be overstrained due to the high technological complexities involved. Second, users might not be willing to contribute to radical innovation projects (barrier of not wanting). This lack of motivation can stem from high anticipated switching costs and from the fear that existing knowledge becomes obsolete $[25,29]$. Due to these barriers companies need to be very careful in selecting users for their radical innovation work. Involving users that are not able to imagine the potential of a radical innovation can lead to fatal managerial decisions. As users might have a negative bias towards the radical innovation, companies that base their decisions on this information alone may break off a project that has the potential for a real breakthrough in the industry. CHRISTENSEN explains the failure of established US firms in their orientation on the voice of mainstream customers. These customers' needs were well met by current technologies. As established firms listened to these customers exclusively their view for technological discontinuities was obstructed. These technological discontinuities, however, form the basis for radical innovations. Mainstream customers induced a technological myopia in the established firms which ultimately led to their failure $[4,9,10]$. Hence, CHRISTENSEN's 
work highlights the importance of a special competence of a firm to leverage the 'right' users for radical innovation projects.

In accordance to CHRISTENSEN's findings, former research points out that the development of radical innovations requires completely different managerial approaches than their incremental counterparts [5,15,20,21]. In particular, market research techniques well suited for incremental innovations have been shown to be of limited value in radical innovation projects $[16,19]$. It is therefore supposed that the user involvement competence of a firm for radical innovations differs significantly from the capability to leverage users for incremental innovations. In order to leverage users for their radical innovation work, organizations need to establish an approach on company level which allows to more systematically select capable users for radical innovations. Our study sheds light on how such a selection approach might look like.

In particular, our paper contributes to technology and innovation management research in two ways. First, by exploring critical user characteristics for distinct phases of the radical innovation process, we provide first insights how manufacturing firms can more effectively identify and leverage valuable users for their radical innovation work. Thereby, we highlight the involvement of capable users as an effective learning mechanism to improve the radical innovation capability of a firm. Second, new perspectives on lead user research are provided by enriching the lead user concept with other crucial characteristics of innovative users.

To study the addressed issue we conducted a multiple case study analysis in the field of medical technology. We find that users with a unique set of characteristics can contribute substantially to the development of radical innovations. These users have a high motivation toward new solutions, are open to new technologies, possess diverse competencies, and are embedded into a very supportive context. Manufacturers that took over the ideas and prototypes of the innovative users benefited significantly. The paper is organized as follows. In the next paragraph we provide theoretical perspectives relevant for the addressed research questions. In the third section we introduce the applied methodology before the findings of our empirical study are presented. Finally, we discuss implications of the findings.

\section{Theoretical perspective}

Which role do users play in the innovation process of radical innovation? To analyse that question the term 'radical innovation' needs to be defined first. Radical innovations are new products or services with a very high degree of innovativeness. According to SALOMO, the 
construct 'innovativeness' encompasses four dimensions: a market dimension, a technological dimension, an organizational dimension, and an external resource-fit dimension [26]. Based on this conceptualization, we define radical innovations as new products or services that create new markets and change existing market structures, provide a new and/or higher customer benefit, induce significant behaviour changes on side of the users, incorporate new and complex technologies, require organizational changes on side of the manufacturing firm, and demand new infrastructures.

Second, a framework for distinct user roles needs to be developed. Such a framework can be based on two dimensions. First, the activity level dimension describes whether users contribute rather actively or passively to new product development. While active contributions contain the development of own solutions to recognized problems, users contribute passively by providing innovation-related information. Examples of active contributions are the development of own ideas and prototypes. Users hereby take over the roles of inventors and developers respectively. Examples of passive contributions are the pure articulation of problems with existing products, requirements, and evaluations. Such contributions are associated with the roles of a claim formulator and an evaluator respectively. Second, the domain dimension describes in which area users contribute. Two domains can be distinguished: the user domain and the technological domain. While activities in the user domain require only use-related knowledge, activities in the technological domain call for technological competencies as well.

To view the role of users for radical innovation from a theoretical perspective, we first consider the activity level dimension. To actively contribute to radical innovations users need to develop creativity and activities that strongly depart from their current use context and conventional solutions. The question is whether users are able therefore. One theory that is fruitful for the analysis of this question is the theory of social perception. This theory claims that perception is controlled by a system of hypotheses that individuals develop by experience [5,6]. By using products repeatedly users form a set of hypotheses with regard to their use context. This set of hypotheses controls what users perceive and therefore limits their mental ability to abstract from the current use context in favour of completely different solutions. Due to their use experience users can underlie a functional fixedness which is a vessel for truly creative thinking $[1,2]$. The hypothesis theory of perception therefore implies a rather pessimistic view on active contributions of ordinary users for radical innovations. If not ordinary users then so called lead users are possibly able to develop solutions for radical innovations. Lead users differ from ordinary users with respect to two characteristics. First, 
lead users face needs months or years before the bulk of the marketplace encounters them. Second, lead users benefit significantly by obtaining a solution to those needs and therefore are highly motivated to engage in the innovation process [33,37]. Empirical studies reveal that lead users indeed exist in several industries and that they are able to develop novel solutions which lead to "next generation products" [17,23,33]. These products have a low to medium degree of innovativeness, but do not match the outlined characteristics of radical innovations. Whether lead users are capable to develop completely different solutions that form the basis for radical innovations therefore remains unclear. Our theoretical considerations lead to the proposition that users are not able to develop own solutions for radical innovations.

With regard to the domain dimension the concept of 'bounded rationality' provides a useful theoretical framework [30,31]. The concept of 'bounded rationality' suggests that the rationality of individuals can - in contrast to neoclassical theory- not be perfect. The reason is that the cognitive capacities of individuals are limited and that individuals therefore are not capable to fully cope with the complexity of their environment. One strategy to cope with this situation is to focus one's activities to specific domains. By concentrating on specific domains, individuals can increase their level of rationality as the complexity of their environment is reduced. This strategy is therefore one of complexity reduction $[12,13]$. The concept of 'bounded rationality' implies the proposition that users will focus their activities in radical innovation projects on the user domain. To contribute within the technological domain users would need to establish technological competencies. As radical innovations are based on new and highly complex technologies the development of these competencies requires a separate education. The strategy of complexity reduction therefore implies a focus on the user domain.

To sum up, our theoretical considerations lead to the proposition that users play a rather passive role in the development of radical innovations and focus their input on the user domain rather than on the technological domain. As we aim to develop a differentiated view of user roles and corresponding user characteristics in distinct phases of the radical innovation process, three generic phases of a NPD process were distinguished: (1) idea generation, (2) development, and (3) testing. As these phases encompass a very different set of activities and prerequisites we propose that critical user characteristics differ in these three phases.

\section{Research approach}


To study the addressed research questions, we conducted an explorative case study analysis in the field of medical technology. The approach of case study research was used due to the nature of the research questions as well as the relatively little knowledge available in the addressed research field. The industry of medical technology was selected for two reasons. First, former empirical studies show that users play an important role for new product development in this industry [3,18,28]. If we observe no innovation activity of users in our case sample, we could conclude that this is rather an effect of the high degree of innovativeness than an industry effect. Second, a number of radical innovations have emerged just recently with new communication and information technologies finding their way into the operating room.

We choose concrete innovation projects as the unit of analysis and applied a multi-casecomparison methodology. Five radical innovation projects were selected, including a medical robot, two computer-assisted navigation systems, a radically new X-ray system and a radically new biocompatible implant. For the selection of truly radical innovations a sevenpoint Likert scale of the degree of innovativeness was used. This scale contains a market dimension, a technological dimension, an organizational dimension, and an external resourcefit dimension [26]. For the selection of appropriate innovations, we focused on firms that are considered to have a pioneering role in medical technology in Germany. The R\&D vice presidents of the participating firms were asked to evaluate major innovations in their firm with regard to this scale. In addition, users were interviewed at medical conferences with respect to the degree of innovativeness that the new products had in their perception. Hereby, the degree of induced behaviour changes and required learning processes when using the new product were crucial indicators. Only those innovations were selected which matched the characteristics of radical innovations by exhibiting a high degree of newness on all three dimensions. To control for memory bias of informants, we only selected projects which were introduced to the market recently. Innovation success was evaluated on the technological and market dimension using a seven-point Likert scale.

Each firm was visited for several weeks to collect the required data. In-depth interviews on the basis of a semi-structured interview guideline were conducted with marketing, $\mathrm{R} \& \mathrm{D}$, project leaders, executive officers and users. In sum a total of 45 interviews were conducted. Each interview had the duration of 2-3 hours. Any interview was recorded on tape and transliterated. The final interview documentation contained approximately 1000 pages. To analyse the collected data, a content analysis framework was used. Therefore, a system of categories for user characteristics and user roles was developed. The category systems were 
developed both deductively (based on existing theories and concepts) as well as inductively (based on the collected data). The inductive component reflects the explorative nature of the study. Each category was specified with several indicators. To control for informant bias which can occur due to different corporate functions or hierarchical levels of informants, only those statements were included into the analysis which had a high degree of agreement between informants. Table 1 provides an overview with regard to the selected radical innovation projects.

$=$ TABLE 1 ABOUT HERE =

In the following section, the findings of the empirical study are presented. According to the distinction of three NPD phases, the findings with regard to user roles and corresponding user characteristics are presented for the ideas generation phase, the development phase, and the testing phase respectively. Finally, the impact of user involvement on the manufacturing firms is pointed out.

\section{Findings}

\subsection{Role of users in the idea generation phase}

First, the role of user in the idea generation phase was explored. We analysed the trigger of the innovative activities, roles of users, and corresponding characteristics in that phase. In four cases (SPOCS, orthoPilot, URS, IMPLANT) users were the original inventors. This observation is in strong contrast to our proposition which states that users are not able to develop own solutions for radical innovations. The question is which factors motivated and enabled users to develop completely new ideas. With respect to motivational factors all inventive users faced severe problems that could not be solved by conventional technologies. For example the neurosurgeons in the cases SPOCS and URS faced precision needs in the sub-millimeter area which could not be met by standard neurosurgical instruments. The experience of coming to the edge with conventional technologies motivated the inventive users to search for completely different solution principles. This type of motivation can be categorized as an extrinsic motivation as it is induced by a specific problem (termed as extrinsic motivation $(P))$.

The idea generation process of the inventive users followed a common pattern in all four cases. Users abstracted from their current use context by searching for relevant technologies 
far outside of their medical domain. Therefore, an openness to new technologies was a key prerequisite that all inventive users shared. Once relevant technologies were recognized, users transferred their solution principles to the medical domain. Thus the inventive users conducted analogical reasoning which is considered as a key source for radically new ideas $[11,14]$. For example, the neurosurgeon in the case URS looked for solutions to prevent the trembling of the neurosurgeon's hand and to realize precision in the sub-millimetre area. In his search for solutions the inventive neurosurgeon looked into nuclear power plants. Analogous to employees in nuclear power plants which need a transmitter between them and the fuel elements a neurosurgeon needs a transmitter between his hand and the patient. By this analogical reasoning the inventive neurosurgeon developed the idea that the principle of kinematics can be applied to neurosurgery. As robotic systems are based on kinematics the idea of a medical robot for neurosurgery was developed.

With regard to enabling factors two types of inventive users could be distinguished. The first type was embedded into a context with close access to interdisciplinary know-how. These users were surgeons at university hospitals which were part of technical universities or which had access to departments of technical universities. This interdisciplinary context inspired truly creative thinking as state-of-the-art technologies could be perceived by surgeons. According to the concept of 'absorptive capacity' (Cohen and Levinthal 1990), access to interdisciplinary know-how increased the creative capacity of the users. Another contextual factor of this user group was the availability of resources for research (time, money, personnel). These resources enabled this group of inventive users to perceive technologies outside of the medical domain and to think about possible technology transfers. The second user type did not have these supportive factors. However, this type exhibited a high amount of intrinsic motivation which compensated the missing contextual factors. Beside a high problem pressure, this user type regarded the search for radically new ideas as a kind of hobby and spent a large amount of spare time on it. Based on the identified characteristics of inventive users an exploratory model can be derived which explains why and how users develop radically new ideas (Figure 1).

\section{$=$ FIGURE $1 \quad$ ABOUT HERE =}

It is interesting to note that the inventive users in our case studies do not match with the classical lead user definition. Although the inventive users were highly motivated to search for new solutions they were no progressive users in the sense that they faced needs which the 
mass market encountered months or years later. The needs and problems that the inventive users had were commonly faced by all users in these medical domains. To illustrate that point we refer to the inventive neurosurgeons. These neurosurgeons did not face future needs as the need for extremely high precision is of concern for the entire community of neurosurgeons. What differentiates the inventive users in our cases than from lead users in the classical sense? The first group of inventive users differs from lead users as they were embedded into a supportive context that inspired and enabled the generation of ideas for radical innovations. Our findings therefore highlight the importance of contextual factors. The second group of inventive users exhibited a strong intrinsic motivation which is also not accounted for in the lead user concept.

The case GCF is contrasting to the other four cases. In that case users did not develop the idea. One explanation can be found in the nature of the idea. The technology of GCF implies minimal pauses of X-Ray exposure which in turn leads to a loss in pictures. The loss of pictures was perceived by radiologists as a danger for misleading diagnostics. Picture loss was regarded as a taboo. The idea of GCF therefore had what can be called a 'prohibitive disadvantage' in the perception of users. This 'prohibitive disadvantage' was a barrier for creative thoughts of radiologists with respect to a GCF technology. In the case of GCF an internal engineer of PHILIPS generated the idea instead.

\subsection{Role of users in the development phase}

Also in the development phase we observed patterns that strongly contradict our theoretically derived propositions. The inventive users took over roles that constitute classical functions of manufacturers. They identified those technological experts (e. g. research institutes) and potential manufacturers that were required to transform their radically new ideas into first prototypes and marketable products. Once they identified relevant partners the inventive users established and organized this innovation network. Obviously, the inventive users took over the networking function in the development process, a role that is classically associated with manufacturers.

To exemplarily illustrate the networking activities of inventive users we refer to the case URS. In that case the neurosurgeon who developed the idea for a medical robot first contacted a graphic artist who visualized his ideas by drawings. Next, the inventive user contacted a graphical design firm to transform the drawings into virtual simulations. These simulations were introduced by the inventive user at several medical conferences. By these publication 
activities the manufacturer SIEMENS got aware of the idea. At that time SIEMENS was in preparation of its 150 anniversary celebration and was looking for feasible visions in medical technology that could be presented at this event. The inventive surgeon contacted SIEMENS which agreed to finance the development of a first prototype. However SIEMENS had no technological knowledge or core competence for the development for a medical robot at that time. In search for a suitable technology partner, the inventive user identified the FRAUNHOFER INSTITUTE as a worldwide leading competence center in robotics. He contacted the engineers of that institute and convinced them to develop a first prototype. The entire budget for this project was provided by SIEMENS.

In the cases SPOCS, orthoPilot, and IMPLANT the inventive users engaged in similar networking activities. This observation raises the question why users took over such a challenging and time demanding role. The explanation might be a combination of several factors. First, the users developed the ideas by themselves without any involvement of technological experts and manufacturers: Users were the original inventors. All inventive users faced severe problems that could not be solved by conventional technologies. The high problem pressure was the driving force not just for the development of ideas, but also for the formation and management of innovation networks.

Second, potential manufacturers were not willing in this early phase to commit themselves to the entire project management of the prospective radical innovations. Manufacturers were rather reluctant to engage into the realisation of the ideas. The reason was that the radical innovations did not meet the core competencies of the manufacturers. Particularly, the innovations did not fit with the technological knowledge base of the manufacturing firms. Manufacturers would have had to build up completely new technological competencies in order to develop the radical innovations. In addition, the manufacturers were deterred by the high technological and market uncertainties associated with these innovations. Radical innovations face the management of a manufacturing firm with unique challenges as the prospective markets are yet unknown and the technology is just emerging [15,19,21,22]. Therefore, the degree of innovativeness is an important variable that might explain why manufacturers did not engage actively in the early phase of the innovation projects and why the inventive users had to fill in this gap. As manufacturers did not pick up the innovative ideas, the inventive users needed to take over an entrepreneurial role at least temporarily.

Third, the inventive users did not have all the competencies and material resources required to transform their ideas into prototypes and marketable products. With regard to competencies users lacked either technological or marketing knowledge. To develop radical 
innovations a combination of market-related knowledge as well as diverse technological competencies are required [20,22]. This entire set of competencies can hardly be possessed by a single user or a team of users alone. Besides competencies, the inventive users did not have all of the financial, human, and marketing resources that were necessary to develop prototypes and marketable products all by themselves. Particularly, users lacked funds, personnel, and sales infrastructure. For this reason, the inventive users were dependent on external support by technological experts and manufacturers. Research on innovation networks highlights a lack of competencies and of resources as an important antecedent for network activities [24,32].

To sum up, a high problem pressure in combination with a reluctant position of manufacturers which is caused by the high degree of innovativeness as well as missing competencies and resources on side of the users form are antecedents for the observed networking activities.

Besides networking the inventive users took over another classical function of manufacturers. The inventive users played the role of developers or (co)-developers. This finding contradicts our proposition which supposes that users are not able to deliver active development contributions for radical innovations. What characteristics enabled users for this role? A case comparison of user characteristics and associated development contributions implies a swell model with separate layers. Each layer can be considered as a critical activity level whereby higher layers are associated with more ambitious and challenging contributions.

The first layer consists of passive development contributions in the user domain. Being the standard routine of ordinary users in incremental innovation projects, our case study analysis reveals that in radical innovation projects even this type of contribution requires distinct characteristics on side of the user. The cases show that users need an extrinsic motivation caused by a current problem, an openness to new technologies, and imagination capabilities. This finding can explain why so called opinion leaders are not necessarily suitable claim formulators in radical innovation projects. Opinion leaders might lack one of these three prerequisites. Particularly, an openness to new technologies can not necessarily be presumed with opinion leaders as their status is often based on conventional technologies. In the cases GCF, URS, and IMPLANT opinion leaders were indeed opponents of the innovations and not capable to provide valid evaluations of concepts and prototypes. The case GCF differs significantly from the other cases. In this case, the perceived 'prohibitive disadvantage' of the GCF technology impeded users to deliver any kind of development contribution at all. 
The next layer constitutes active development contributions in the user domain. The case studies reveal that users need an additional set of characteristics to perform on that layer. First, users need to have a high competence in their own domain. The reason is that this layer contains the development of own solutions. To develop own solutions for radical innovations one needs to have a profound understanding of the elements, the causes, and effects of a certain domain. In addition, users need to have tolerance of ambiguity. This characteristic means that users must be able to handle a high amount of uncertainty with respect to the final output of their development efforts. In the early phases of the radical innovation process a developing user does not know, whether his efforts actually lead to a feasible solution. Users therefore face a high amount of uncertainty. The case study analysis reveals that active development contributions require two contextual characteristics in addition. First, users need to have access to technological know-how. The explanation for the importance of this contextual factor is twofold. On the one hand, users rely on complementary technological knowledge for the development of own solutions in their domain. For example, the team of innovative users in the case IMPLANT developed a camera system to measure the pressure on the abdominal wall. For this development the users were dependent on technological knowledge with regard to camera systems. On the other hand, access to technological knowhow is critical for innovative users in order to get immediate response with respect to the technological feasibility of their solutions. This feed-back can be leveraged by an innovative user in an iterative process to improve the own solution. In the case orthoPilot the innovative user developed the biomechanical solution of the computer-assisted navigation system for orthopaedics. By having access to technological knowledge of computer science which was hold by the co-developing engineer, the innovative user was able to iteratively improve his solution in the medical domain. Second, users need resources for own research activities. One explanation why this contextual characteristic is critical on that layer might be the high complexity of such a task. The development of radically new solutions in the user domain is a highly complex and challenging task. In addition, this task does have a high degree of newness to the user. Therefore, users need to intensively deal with the specific subject at hand. For these highly creative activities users need intellectual free space and resources such as time, facilities, and funds. To sum up, specific characteristics enable users to realize active development contributions in their own domain. Considering these characteristics, it becomes evident that users as development partners for radical innovations need to have a completely different profile as those users that are associated with conventional marketing research. 
To reach the highest layer, active development contributions in the technological domain, users additionally need technological competencies. The case SPOCS illustrates that point. In this case a team of innovative neurosurgeons developed not just the idea, but also a first prototype of a computer-assisted navigation system for neurosurgery. This was possible as the users combined all the complementary technological knowledge that was necessary for this development. The required technological knowledge contained know-how on mechanics, computer programming, and electronics. One innovative user was a professional watch maker before he started his educational track for neurosurgery. He therefore had the technological know-how with respect to mechanics. Another user trained himself auto-didactically computer programming until he had profound computer programming skills. Yet another neurosurgeon on that user team had a profound background in electronics. Obviously users with a diverse set of technological capabilities ('cross-qualification') are a relevant group as development partners for radical innovations. Our case study analysis reveals that users that are capable to perform on this highest layer are rather the exception than the normal case. Mostly users focused their development activities on the user domain. One explanation for this observation lies in the nature of radical innovations. These innovations incorporate new and highly complex technologies. To develop the according technological know-how requires a separate education. Most users do not have the time as well as the absorptive capacity therefore. The empirical evidence confirms our proposition with respect to the dominant domain of users' development contributions. The swell model with its three distinct layers is illustrated in Figure 2.

\section{$=$ FIGURE 2 ABOUT HERE $=$}

The model provides a framework that explains which characteristics enable distinct development contributions by users in radical innovation projects. Still open, however, is the question what drives users to realize specific layers. One proposition is that the extent of motivation plays a critical role: higher layers require a higher amount of motivation on side of the user. One explanation for this proposition is that higher layers demand higher cognitive and temporal effort on side of the users.

\subsection{Role of users in the testing phase}

Besides the profile of highly creative users and of users as (co)-developers, companies need to know the characteristics of those users that are willing and able to successfully test early 
versions of radical innovations. The case study analysis reveals that the capability of a firm to select suitable testing partners is crucial for the success of radical innovations. The case comparison shows that the profile of users that were capable to successfully test prototypes of radical innovations differs significantly from the profile of users that failed. Companies that relied on 'conventional' characteristics for the selection of testing partners had a high failure rate of prototype tests. These characteristics that are at the focus of conventional marketing research methods included opinion leadership, representativeness, and high sales volume of the user. Obviously, the characteristic of opinion leadership is not a guarantee that this user is capable to successfully test prototypes of radical innovations. The same holds true for representative users or users that have a high sales importance for the innovating company. What profile of characteristics do successful testers have? First, these users have a high 'innovation tolerance'. This tolerance includes openness for new technologies, willingness to take risks, and willingness to experiment. The disposition of such an 'innovation tolerance' allows users to bear the uncertainties, risks and iterations that the testing process of radical innovations requires. In addition, a geographical proximity to the innovating company proved to be a critical contextual factor of successful prototype tests. As early versions of radical innovations mostly have several bugs, an intense face-to-face interaction between the innovating company and the user is essential in the testing phase. A high geographical proximity supports such an interaction pattern.

\subsection{Impact of user contributions for manufacturing firms}

Our case study analysis reveals that the users' contributions had a high positive impact on those manufacturers that finally took over the ideas and prototypes of the inventive users. The involvement of capable users therefore proved to be an effective learning mechanism to improve the radical innovation capability of these firms (Table 2).

\section{$=$ TABLE 2 ABOUT HERE =}

In those cases in which users played multiple roles as inventors, networkers, developers, and testers (SPOCS, orthoPilot, URS, IMPLANT) the involved manufacturers benefited significantly. In these cases, manufacturers not just gained ideas for radical innovations. The networking activities of the inventive users also impacted positively on development time and -costs. The active development contributions of the inventive users led to substantial 
improvements of product quality. The testing role of the inventive users accounted for an increase in use friendliness of the radical innovations which turned out to be an important factor for market acceptance. Finally, the information provided by the inventive users led to an improvement of the manufacturers' decisions. Based on the users' information the manufacturers selected the 'right' prototypes and set the 'right' priorities. The case GCF presents a different picture. In that case users were deterred by the 'prohibitive disadvantage' of the technology and evaluated the radical innovation extremely negatively. This negative feed-back led to an increase of internal barriers at PHILIPS. Users supplied internal opponents with arguments against the innovation. From a retrospective the increase of internal barriers was a negative impact of user involvement as GCF turned out to be a highly successful innovation. To sum up, the contributions of the inventive users implied a substantial positive impact for the manufacturers that later introduced the radical innovations into the market. This finding implies the recommendation for manufacturers to systematically leverage users with a specific set of characteristics for their radical innovation work.

\section{Conclusions}

Our findings have implications for innovation and marketing research as well as for corporate practice. The case study analysis reveals that the profile of users that are in the position to develop radical innovations differs significantly from those users types that are typically involved in conventional marketing research. Consequently, radical innovations require a completely different marketing research approach. Is the lead user concept a suitable approach? With regard to this question, it is important to note that the inventive users in our case sample do not meet the classical lead user definition. However, the inventive users in our case sample share some characteristics that are associated with lead users. First, the inventive users had a high motivation for the development of new solutions. Second, the inventive users in the cases SPOCS and URS were neurosurgeons which can be categorized as extreme users as they faced the need for extremely high precision. The group of extreme users was identified as relevant for the search of lead users [17,38]. We therefore conclude that the inventive users have certain similarities with lead users. However, our analysis reveals that additional characteristics are needed to contribute substantially to the development of radical innovations. Such characteristics include an openness to new technologies, an embeddedness into a supportive context (resources, access to interdisciplinary know-how), and an intrinsic motivation. The observation that in four of five cases users dominated the entire development 
process implies that the user active paradigm [39] can also appear in radical innovation projects. This contradicts mainstream thinking whereby radical innovations are dominated by manufacturers. Particularly, the observed networking function and the according 'entrepreneurial' role of the inventive users is an interesting aspect for further user innovation research. If some users are able to dominate the innovation process of radical innovations, we might need to re-think our conventional wisdom that manufacturers involve users in radical innovation projects. Rather users involved manufacturers in the development process at a time where they lacked the required competencies and resources to proceed by their own. This thinking implies that we need to develop characteristics of suitable manufacturers as cooperation partners of inventive users. Turning conventional lead user thinking around, we would rather look for 'lead manufacturers' as proper partners for inventive users.

With respect to corporate practice, the identified characteristics of inventive users can be leveraged by manufacturers as a search grid to more systematically identify highly creative users. The identification of such creative users can increase the creative capacity of a manufacturer as radically new ideas and solutions can be gained. One important dimension of the organizational competence for radical innovation therefore is the capability to identify this group of high potential users. In similar form the swell model can be used as a search grid for the identification of such users that can play the role of (co)-developers for radical innovations. The swell model implies a conceptual thinking in 'user pyramids'. We assume that the number of users decreases with higher layers as higher layers are more challenging and require additional characteristics. Consequently, we suppose that it is far more difficult for manufacturers to identify users on top of the pyramid (users capable for active development contribution in technological domain) as to identify users at the bottom of the pyramid (users capable for passive development contributions in the user domain). As only very few users are capable to deliver productive contributions for radical innovations, manufacturers need to conduct the user selection process very diligently. Particularly, for small and medium sized manufacturers the identification of users that take over large parts of the development process is a useful strategy to develop radical innovations despite R\&Dbudget restrictions.

Recapitulating, our study sheds light on the role of users for radical innovation and discovered rather surprising results. It needs to be taken into account, however, that our study was exploratory in nature and contained only five radical innovation projects. Therefore, one critical question is whether the identified patterns can be observed in other industries as well. The industry of medical technology has specific characteristics that limit the generalization of 
our results. One important speciality of the industry of medical technology that is highly relevant for the focus of our study is that users in this industry are professional users. Therefore, the observed users differ from users that use certain products as part of their hobby (e.g. mountain bikers). Further research should extend our study to other industries. Another avenue for further research is to test our exploratory models by large scale, quantitative studies.

\section{References}

1 Allen, T.J. \& Marquis, D.G. (1964) Positive and negative biasing sets: The effects of prior experience on research performance, IEEE Transactions on Engineering Management, Vol. 11, No. 4, pp. 158-161.

2 Birch, H.G. \& Rabinowitz, H.J. (1951) The negative effect of previous experience on productive thinking, Journal of Experimental Psychology, Vol. 47, No. 2, pp. 121-125.

3 Biemans, W. (1991) User and third-party involvement in developing medical equipment innovations, Technovation, Vol. 11, No. 3, pp. 163-182.

4 Bower, J.L., Christensen, C.M., (1995) Disruptive technologies: Catching the wave. Harvard Business Review, Vol. 73, No. 1, pp. 43-53.

5 Bruner, J.S. (1957) On perceptual readiness, Psychological Review, Vol. 64, pp. 123152.

6 Bruner, J.S. \& Postman, L. (1951) An approach to social perception, in: Current trends in social psychology, W. Dennis and R. Lippitt, eds. Pittsburgh: University of Pittsburgh Press.

7 Chandy, R.K., Tellis, G.J., (1998) Organizing for radical product innovation. Marketing Science Insitute, Cambridge, MA.

8 Christensen, C.M., (1997) The innovator's dilemma: When new technologies cause great firms to fail, Harvard Business School Press, Boston.

9 Christensen, C.M.; Bower, J.L., 1995. Customer power, strategic investment, and the failure of leading firms, Strategic Management Journal Vol. 17, pp. 197-218.

10 Cohen, W.M.; Levinthal, D.A. (1990) Absorptive capacity: A new perspective on learning and innovation, Administrative Science Quarterly, Vol. 35, No. 1, pp. 128 152. 
11 Dahl, D.W.; Page Moreau, P. (2002) The influence and value of analogical thinking during new product ideation, Journal of Marketing Research, Vol. 39, No. 2, pp. 4760.

12 Dequech, D. (2001) Bounded rationality, institutions, and uncertainty, Journal of Economic Issues, Vol. 35, No. 4, pp. 911-929.

13 Gigerenzer, G. (2001) The adaptive toolbox, in: Bounded rationality: The adaptive toolbox, G. Gigerenzer, and R. Selten, eds. Cambridge, MA: The MIT Press, pp. $37-$ 50.

14 Holyoak, K.J. \& Thagard, P. (1995) Mental Leaps: Analogy in creative thought, Cambridge, MA: MIT Press.

15 Leifer, R., McDermott, C.M., O'Connor, G.C., Peters, L., Rice, M., Veryzer, R. (2000) Radical innovation: How mature companies can outsmart upstarts, Harvard Business School Press, Boston.

16 Lettl, C., (2004) Die Rolle von Anwendern bei hochgradigen Innovationen: Eine explorative Fallstudienanalyse in der Medizintechnik, Deutscher Universitäts-Verlag, Wiesbaden.

17 Lilien, G.L., Morrison, P.D., Searls, K., Sonnack, M.; von Hippel, E. (2002) Performance assessment of the lead user idea-generation process for new product development, Management Science, Vol. 48, Vol. 8, pp. 1042-1059.

18 Lüthje, C. (2003) Customers as co-inventors: An empirical analysis of the antecedents of customer-driven innovations in the field of medical equipment, Proceedings of the 32nd Annual Conference of the European Marketing Academy (EMAC), Glasgow.

19 Lynn, G.S., Morone, J.G., Paulson, A.S., (1996) Marketing and discontinuous innovation: The probe and learn process, California Management Review, Vol. 38, Vol. 3, pp. 8-37.

20 McDermott, C. (1999), Managing radical product development in large manufacturing firms: A longitudinal study, Journal of Operations Management, Vol. 17, No. 6, pp. 631-644.

21 McDermott, C.; O'Connor, G. (2002) Managing radical innovation: an overview of emergent strategy issues, The Journal of Product Innovation Management, Vol. 19, pp. 424-438.

22 O'Connor, G.; Veryzer, R. (2001) The nature of market visioning for technology-based radical innovation, The Journal of Product Innovation Management, Vol. 18, pp. 231246. 
23 Olson, E.L.; Bakke, G. (2001) Implementing the lead user method in a high technology firm: A longitudinal study of intentions versus actions, The Journal of Product Innovation Management, Vol. 18, No. 2, pp. 388-395.

24 Pyka, A. (2002) Innovation networks in economics: From the incentive-based to the knowledge-based approaches, European Journal of Innovation Management, Vol. 5, No. 3, pp. 152-63.

25 Ram, S.; Sheth, J.N. (1989) Consumer resistance to innovations: The marketing problem and its solutions, The Journal of Consumer Marketing, Vol. 6, No. 2, pp. 513.

26 Salomo, S., (2003). Konzept und Messung des Innovationsgrades - Ergebnisse einer empirischen Studie zu innovativen Entwicklungsvorhaben, in: Empirie und Betriebswirtschaft: Entwicklungen und Perspektiven, Schwaiger, M., Harhoff, D. (Eds.), Schäfer-Poeschel, Stuttgart, pp. 399-427.

27 Schoormans, J.P., Orrt, R.J., de Bont, J.P. (1995). Enhancing concept test validity by using expert consumers, The Journal of Product Innovation Management, Vol. 12, No. 2, pp. 153-162.

28 Shaw, B. (1985), The role of the interaction between the user and the manufacturer in medical equipment innovation, $R \& D$ Management, Vol. 15, No. 4, pp. 283-292

29 Sheth, J.N., (1981), Psychology of innovation resistance: The less developed concept (LDC) in diffusion research, Research in Marketing, Vol. 4, pp. 273-282.

30 Simon, H. (1957), Administrative behavior. New York: Macmillan.

31 ---- (1996), Bounded rationality, in: The New Palgrave, Eatwell, J. et al., (Eds.), London, Macmillan.

32 Soh, P.-H. \& Roberts, E. (2003), Networks of innovators: a longitudinal perspective, Research Policy, Vol. 32, No. 9, pp. 1569-88.

33 Urban, G.L.; von Hippel, E. (1988), Lead user analyses for the development of new industrial products, Management Science, Vol. 34, No. 5, pp. 569-582.

34 Urban, G.L., Weinberg, B.D.; Hauser, J.R. (1996), Premarket forecasting of really new products, Journal of Marketing, Vol. 60, No. 1, pp. 47-60.

35 Veryzer, R.W. (1998), Key factors affecting customer evaluation of discontinuous new products, The Journal of Product Innovation Management, Vol. 15, No. 2, pp. 136150.

36 ----, 1998, Discontinuous innovation and the new product development process. The Journal of Product Innovation Management, Vol. 15, No. 4, pp. 304-321. 
37 von Hippel, E. (1986), Lead users: A source of novel product concepts, Management Science, Vol. 32, No. 7, pp. 791-805.

38 von Hippel, E, Thomke,S.H.; Sonnack, M. (2000), Creating breakthroughs at 3M, Health Forum Journal, Vol. 43, No. 4, pp. 20-27.

39 von Hippel, E. (1979) A customer-active paradigm for industrial product idea generation, Industrial Innovation, M. Baker, (Ed.), London, The Macmillan Press. pp. 82-110. 
Table 1: Selected radical innovations for case study analysis

\begin{tabular}{|c|c|c|c|c|c|}
\hline Case & Product description & Manufacturer & \multicolumn{2}{|c|}{ Innovation success } & Number of \\
\hline SPOCS & $\begin{array}{l}\text { Computer-assisted navigation } \\
\text { system for neurosurgery }\end{array}$ & AESCULAP & $\begin{array}{l}\text { MS: } \\
\text { TS: }\end{array}$ & $\begin{array}{l}\text { medium } \\
\text { high }\end{array}$ & 9 \\
\hline orthoPilot & $\begin{array}{l}\text { Computer-assisted navigation } \\
\text { system for orthopaedics }\end{array}$ & AESCULAP & $\begin{array}{l}\text { MS: } \\
\text { TS: }\end{array}$ & $\begin{array}{l}\text { high } \\
\text { high }\end{array}$ & 10 \\
\hline URS & Robotic system for neurosurgery & $\begin{array}{l}\text { FRAUNHOFER } \\
\text { INSTITUTE }\end{array}$ & $\begin{array}{l}\text { MS: } \\
\text { TS: }\end{array}$ & $\begin{array}{l}\text { medium } \\
\text { high }\end{array}$ & 8 \\
\hline IMPLANT & Biocompatible implant & Anonymous & $\begin{array}{l}\text { MS: } \\
\text { TS: }\end{array}$ & $\begin{array}{l}\text { high } \\
\text { high }\end{array}$ & 9 \\
\hline GCF & $\begin{array}{l}\text { X-ray system based on grid- } \\
\text { controlled fluoroscopy }\end{array}$ & PHILIPS & $\begin{array}{l}\text { MS: } \\
\text { TS: }\end{array}$ & $\begin{array}{l}\text { high } \\
\text { high }\end{array}$ & 9 \\
\hline
\end{tabular}

Note: $\mathrm{MS}=$ Market success, $\mathrm{TS}=$ Technological success

Table 2: Impact of user contributions on manufacturers

\begin{tabular}{|l|c|c|c|c|c|}
\hline \multicolumn{1}{|c|}{ Case } & SPOCS & $\begin{array}{c}\text { Portho } \\
\text { Pilot }\end{array}$ & URS & GCF & IMPLANT \\
\hline Acquisition of idea for radical innovation & $X$ & $X$ & $X$ & & $X$ \\
\hline Reduction of development time & $X$ & $X$ & $X$ & & $X$ \\
\hline Reduction of development cost & $X$ & $X$ & $X$ & & $X$ \\
\hline Substantial improvement of product quality & $X$ & $X$ & & & $X$ \\
\hline Increase in use friendliness & $X$ & $X$ & $X$ & & $X$ \\
\hline Improvement of decision quality & $X$ & $X$ & $X$ & & $X$ \\
\hline Increase of internal barriers & & & & $X$ & \\
\hline
\end{tabular}


Figure 1: $\quad$ Users as inventors of radical innovations - an exploratory model

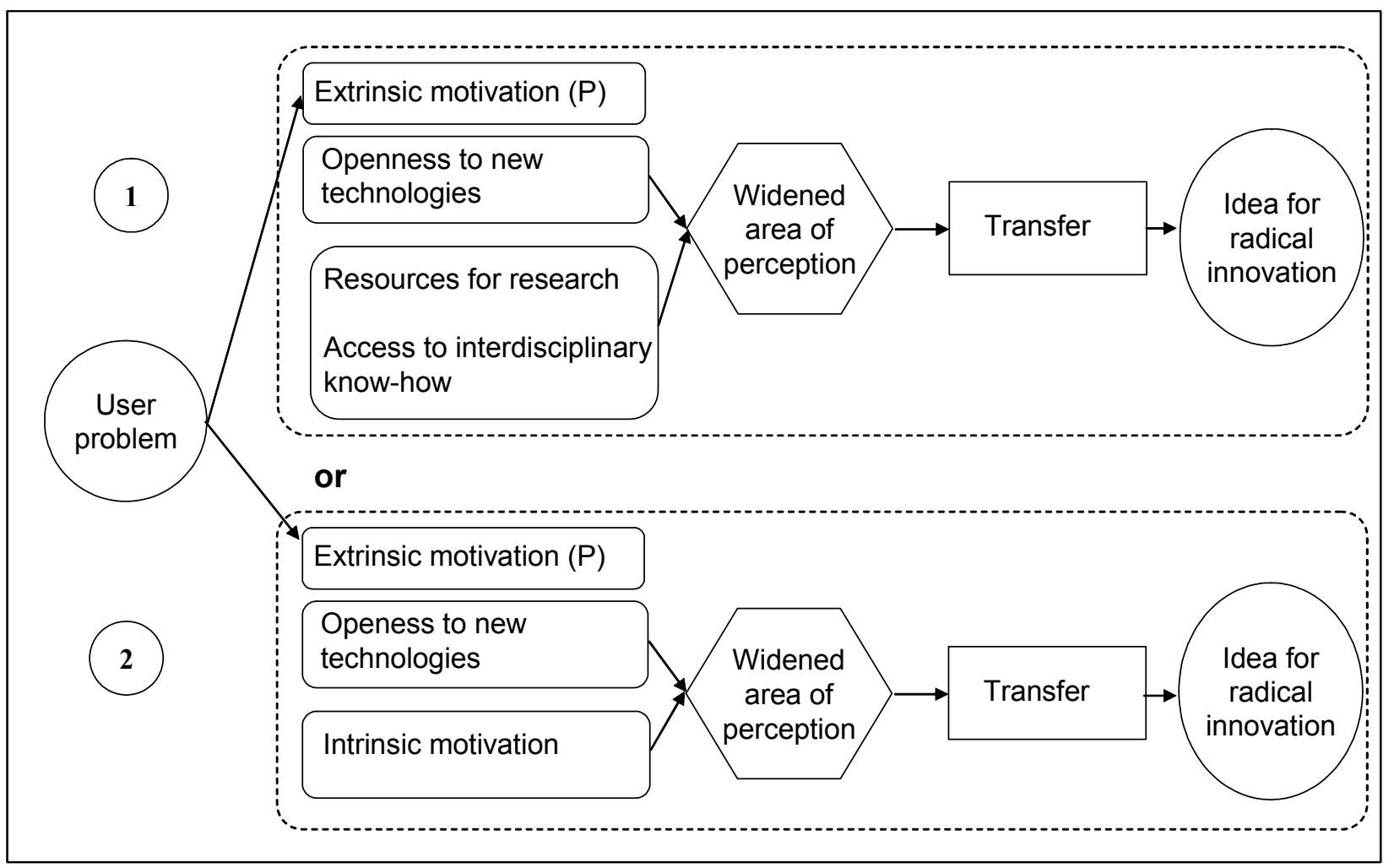


Figure 2: Swell model of development contributions by users for radical innovations

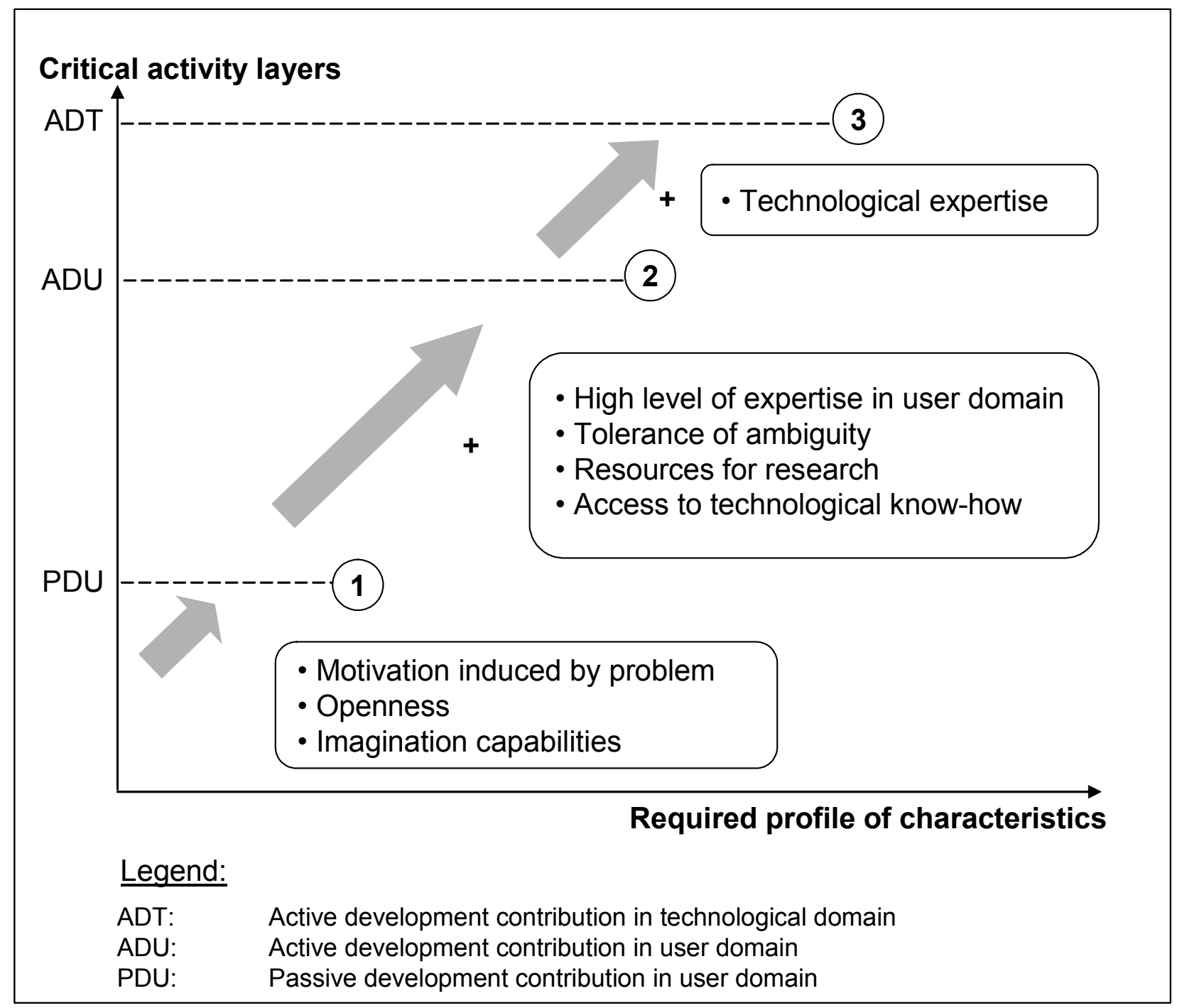

